\title{
Inbreeding effects on fetal growth and development*
}

\author{
P S S RAO AND S G INBARAJ
}

From the Department of Biostatistics, Christian Medical College, Vellore 632 002, Tamil Nadu, India

SUMMAKY The effects of inbreeding on the incidence of congenital anomalies and measurement at birth of offspring were explored on the basis of a prospective survey done during 1969 to 1974 . The pregnancies of over 20000 married women from rural and urban samples in North Arcot District were identified and followed up through routine home visiting once every 5 weeks by qualified women investigators. Of all marriages, $47 \%$ in the rural areas and $29 \%$ in the urban were consanguineous. The average inbreeding coefficients in the rural and urban areas were 0.0371 and 0.0204 , respectively; these are significantly higher than those prevalent in most parts of the world.

For purposes of statistical analysis, marriages were classified into four groups based on degree of consanguinity. Women in these four marriage groups were similar in terms of major social, economic, and other demographic factors, and in maternal variables, such as the time since the last pregnancy, place of delivery, and attendant at delivery.

No significant differences existed in the incidence of congenital anomalies among offspring between the consanguineous and non-consanguineous marriages in the rural or in the urban area. Neither were any significant trends seen by degree of consanguinity, or by birth order, or by the different age groups. The types of malformations and their frequency seen in the consanguineous and non-consanguineous groups were similar. There were also no significant differences observed by type of marriage in both areas in gestational age, birthweight, body length, head circumference, or chest circumference. The fitting of exponential curves relating inbreeding coefficients to these indices led to regressions that do not attain statistical significance. It is suggested that long term inbreeding does not lead to appreciable effects on fetal growth and development.

Variable conclusions have been drawn in studies dealing with the effects of inbreeding on prereproductive mortality and reproductive wastage. ${ }^{1}$ The role of inbreeding in shaping fetal growth and development seems even more unclear. Many attractive hypotheses have been postulated regarding inbreeding effects on quantitative characteristics, ${ }^{2}$ but more real data are necessary to test them. Anthropometrics of the growing embryo depend heavily on non-genetic factors and this fact must be taken into account in inferring any inbreeding effects. The incidence of consanguinity has declined to very low frequencies in most parts of the world, and those still undertaking these marriages in such areas are likely to belong to different socioeconomic groups compared to the general population.2a Genetic effects are thus confounded with environmental and

\footnotetext{
*Financed by the National Center for Health Statistics, Public Health Service, Department of Health, Education and Welfare, Washington DC 20201, USA under Agreement No 01-657-2 NCHS-IND-7.

Received for publication 16 May 1979
}

other non-genetic influences, thereby restricting the value of inbreeding studies in those areas. In contrast, the vast population of south India, who still prefer consanguineous marriages, offers excellent scope for a study of inbreeding effects on human growth and development. ${ }^{3}$ On the basis of a comprehensive community study on infant mortality carried out in Tamil Nadu State during 1969 to 1974, the effects of consanguineous marriages on couples' fertility and sterility were discussed in an earlier paper. ${ }^{4}$ In a continuing series of articles from this prospective community study, the role of parental consanguinity on the occurrence of congenital malformations, gestational age, and birth measurements are presented in this paper.

\section{Material and methods}

The study was carried out in rural and urban areas of North Arcot District in Tamil Nadu State in south India. The demographic characteristics of the district have been described in our earlier report. ${ }^{4}$ Almost 
one full community development block was chosen to provide the rural sample of about 50000 persons. One-third of Vellore town was selected through stratified random sampling procedures as the urban sample of about $\mathbf{4 0} 000$ persons.

Women interviewers who were fluent in the local language (Tamil) and who had some background in health sciences were appointed and given adequate training. Each interviewer was responsible for an area of about 4000 population in the rural or about 5000 in the urban area. For every four interviewers there was a supervisor (female) and a co-ordinator (male). Demographic surveys were initially done to map all houses and identify all residents. During the initial visits to each household a general profile on social, economic, and demographic aspects was obtained and every married woman was interviewed intensively on her past reproductive history. As described earlier, ${ }^{4}$ every marriage was screened for the existence and type of consanguinity by drawing pedigrees upwards for two generations on the side of both spouses, and confirmed by at least two adults in the family. To determine any inconsistencies, $5 \%$ were reinterviewed by supervisory personnel.

Each currently married woman in the reproductive age group was entered into the follow-up survey and visited once every 5 weeks to obtain details of last menstrual period and other related data. Those who had missed their menstrual period for 5 weeks or more were continued under 'pregnancy follow-up' until termination or completion of pregnancy or resumption of menstruation, after which they were assigned to the routine follow-up. Each liveborn child was visited within $\mathbf{4 8}$ hours of birth for recording of sex and gestational age, obtaining of birth measurements, and detection of congenital malformations. Weight was measured using a beam balance up to an accuracy of $5 \mathrm{~g}$; length (crown-heel and crown-rump) was obtained using an indigenous infantometer, and head and chest circumference by a cloth tape, with an accuracy of $0.5 \mathrm{~cm}$. Congenital malformations included only those externally manifested anomalies that could be easily detected by qualified lay interviewers using standard screening procedures.

Completed records were routinely scrutinised for any discrepancies which were rectified and then sent for abstraction of relevant data onto punch cards. Routine statistical tables were prepared for review and quality control. Final analyses were done through IBM 360/370 computer systems.

\section{Results}

The average inbreeding coefficients in the rural and urban areas were 0.0371 and 0.0204 , respectively; these are significantly higher than the rate prevalent $\stackrel{\mathbb{P}}{=}$ in most parts of the world. Of the total marriages, $47 \%$ in the rural and $29 \%$ in the urban areas were consanguineous.

For purposes of statistical analysis, parental $\frac{\bar{\sigma}}{\bar{m}}$ consanguinity was classified into four types: (1) $\vec{\nabla}$

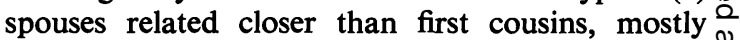
uncle-niece (UN); (2) spouses who were first os cousins (FC); (3) spouses whose relationship was $\vec{O}$ beyond that of first cousins (BFC); and (4) spouses $\overrightarrow{-}$ who were unrelated or non-consanguineous (NC).

In more than $80 \%$ of the consanguineous marriages, the spouses were first cousins or moreco closely related, as seen in table 1 .

The distributions by major social and economic $-\overrightarrow{-}$ variables did not reveal any significant differences ${ }_{y}$ among the four marriage groups.

During the study a total of 14243 pregnancies were recorded which included 10685 single liveborn $7 \pi$ children. In the four marriage types, the numbers were distributed as shown in table 2 .

The distribution by birth order and maternal age in the four marriage groups did not differ signifi- $\vec{\bullet}$ cantly from one another. Similarly, variables such $ळ$ as the time since the last pregnancy, educational and occupational status of the mother and father, and place of and attendant at delivery, appeared to be distributed similarly in the different marriage groups.

\section{CONGENITAL MALFORMATIONS}

The incidence of congenital malformations per $1000 \overrightarrow{\bar{O}}$ liveborn in the rural and urban areas was 6.9 and 3

TABLE 1 Distribution of women by type of consanguineous marriage

\begin{tabular}{|c|c|c|c|c|}
\hline \multirow[t]{2}{*}{ Type of consanguinity } & \multicolumn{2}{|l|}{ Rural } & \multicolumn{2}{|c|}{ Urban } \\
\hline & No & $\%$ & No & $\%$ \\
\hline $\begin{array}{l}\text { Non-consanguineous } \\
\text { Consanguineous } \\
\text { Beyond second cousins } \\
\text { Second cousins } \\
\text { First cousins once removed } \\
\text { First cousins } \\
\text { Uncle-niece and aunt- } \\
\text { nephew* }\end{array}$ & $\begin{array}{r}6169 \\
5459 \\
70 \\
269 \\
393 \\
2886 \\
\\
1841\end{array}$ & $\begin{array}{r}53 \cdot 1 \\
46 \cdot 9 \\
0 \cdot 6 \\
2 \cdot 3 \\
3 \cdot 4 \\
24 \cdot 8 \\
15 \cdot 8\end{array}$ & $\begin{array}{r}6378 \\
2620 \\
50 \\
143 \\
265 \\
1573 \\
\\
589\end{array}$ & $\begin{array}{r}70 \cdot 9 \\
29 \cdot 1 \\
0 \cdot 5 \\
1 \cdot 6 \\
3 \cdot 0 \\
17 \cdot 5 \\
6 \cdot 6\end{array}$ \\
\hline
\end{tabular}

*Only 5 aunt-nephew marriages noted.

TABLE 2 No of pregnancies observed according to parental consanguinity

\begin{tabular}{lcc}
\hline Parental relationship & Rural & Urban \\
\hline NC & 4449 & 4251 \\
C & 3889 & 1654 \\
BFC & 590 & 294 \\
FC & 1991 & 989 \\
UN & 1308 & 371 \\
Total & 8338 & 5905 \\
\hline
\end{tabular}


$10 \cdot 4$, respectively. The incidence among the consanguineous and non-consanguineous marriages is shown in table 3.

The rate among the consanguineous marriages was lower compared to the non-consanguineous in the rural area, but in the urban area the opposite was seen. However, the differences in both the areas fail to achieve statistical significance. There were no significant trends by degree of relationship in either area or when examined by birth order (table 4) and maternal age (table 5).

In the rural area, the earlier birth orders showed a higher incidence of congenital malformations among the consanguineous compared to the nonconsanguineous marriages, while in the later birth orders the incidence was lower in the consanguineous marriages. The picture in the urban area seemed to be similar. However, none of these differences attain statistical significance. Detailed analyses using all four marriage groups failed to reveal any significant trends by degree of consanguinity.

In the rural area, in all but the youngest age group, the incidence of congenital malformations among the consanguineous was lower than that among the non-consanguineous marriages. In the

TABLE 3 Incidence of congenital malformations by parental consanguinity (per 1000 liveborn)

\begin{tabular}{llc}
\hline Parental relationship & Rural & Urban \\
\hline NC & 7.7 & 9.7 \\
C & 5.9 & $12 \cdot 2$ \\
BFC & 0.0 & 17.9 \\
FC & 7.3 & 10.9 \\
UN & 6.2 & $11 \cdot 1$ \\
Total & 6.9 & 10.4 \\
\hline
\end{tabular}

TABLE 4 Incidence of congenital malformations by consanguinity and birth order (per 1000 liveborn)

\begin{tabular}{llllrr}
\hline Birth order & \multicolumn{2}{l}{ Rural } & & \multicolumn{2}{l}{ Urban } \\
\cline { 2 - 3 } \cline { 5 - 6 } \cline { 5 - 6 } & $N C$ & $C$ & & \multicolumn{1}{c}{$C$} \\
\hline 1,2 & $6 \cdot 0$ & $7 \cdot 8$ & $6 \cdot 9$ & $16 \cdot 3$ \\
$3,4,5$ & $9 \cdot 6$ & $6 \cdot 2$ & $8 \cdot 5$ & $9 \cdot 3$ \\
6 or more & $5 \cdot 4$ & $3 \cdot 4$ & $12 \cdot 5$ & $12 \cdot 2$ \\
\hline
\end{tabular}

TABLE 5 Incidence of congenital malformations by consanguinity and maternal age (per 1000 liveborn)

\begin{tabular}{|c|c|c|c|c|}
\hline \multirow[t]{2}{*}{ Maternal age (yr) } & \multicolumn{2}{|c|}{ Rural } & \multicolumn{2}{|c|}{ Urban } \\
\hline & $N C$ & $C$ & $N C$ & $C$ \\
\hline $\begin{array}{l}15-19 \\
20-24 \\
25-29 \\
30-49\end{array}$ & $\begin{array}{l}7 \cdot 2 \\
6 \cdot 5 \\
6 \cdot 5 \\
9 \cdot 8\end{array}$ & $\begin{array}{r}11 \cdot 7 \\
5 \cdot 7 \\
3.8 \\
5 \cdot 0\end{array}$ & $\begin{array}{r}6 \cdot 0 \\
5 \cdot 1 \\
7 \cdot 7 \\
17 \cdot 5\end{array}$ & $\begin{array}{r}25 \cdot 2 \\
10 \cdot 0 \\
9 \cdot 1 \\
11 \cdot 8\end{array}$ \\
\hline
\end{tabular}

urban area, the rates for consanguineous were higher than those for non-consanguineous marriages, up to the age of 30 years, beyond which they were lower. Again, however, the differences do not attain statistical significance, even in the youngest age group which shows higher values. The type of malformations observed in the consanguineous and non-consanguineous marriages are given in table 6.

With the small sample sizes, it is difficult to compute type-specific rates and expect statistical significance. A perusal of table 6 shows, however, that the types of malformation seen in the consanguineous marriages are similar to, and occur no more often than, those seen in the non-consanguineous group.

\section{GESTATIONAL AGE}

The proportion of babies who were born at less than 37 weeks' gestation in the rural and urban areas were $21.1 \%$ and $19.7 \%$, respectively. The proportions in relation to parental consanguinity are shown in table 7 . The proportion among the consanguineous

TABLE 6 Type of congenital malformation by parental consanguinity

\begin{tabular}{|c|c|c|c|c|}
\hline \multirow[t]{2}{*}{ Type of malformation } & \multicolumn{2}{|c|}{ Rural } & \multicolumn{2}{|c|}{ Urban } \\
\hline & $N C$ & $C$ & $N C$ & $C$ \\
\hline Anencephalus & - & - & - & 1 \\
\hline Hydrocephalus & 1 & 1 & 1 & 1 \\
\hline Anomalies of ear & - & 1 & 1 & 1 \\
\hline Cleft palate & - & 1 & 一 & 一 \\
\hline Cleft lip, with or without & & & & \\
\hline palate & 3 & 3 & 1 & 2 \\
\hline Anomalies of the tongue & 一 & 1 & 1 & 一 \\
\hline Imperforate anus & 1 & 1 & 4 & - \\
\hline Anomalies of genitals & 2 & - & 1 & - \\
\hline Club foot & 5 & 3 & 6 & 5 \\
\hline Polydactyly & 11 & 5 & 5 & - \\
\hline Absence of fingers or toes & - & - & 1 & 2 \\
\hline $\begin{array}{l}\text { Anomalies of musculoskeletal } \\
\text { system }\end{array}$ & 1 & 1 & 3 & 1 \\
\hline Down's syndrome & - & - & 2 & 1 \\
\hline Congenital blindness & - & - & - & 1 \\
\hline $\begin{array}{l}\text { Imperforate anus and other } \\
\text { anomaly }\end{array}$ & 1 & - & 1 & - \\
\hline Anomalies of eye or face & - & - & 1 & 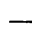 \\
\hline Indeterminate sex & - & - & 1 & 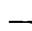 \\
\hline Anomalies of skin & - & - & 2 & - \\
\hline Other specific anomalies & 1 & - & 2 & - \\
\hline Total & 26 & 17 & 31 & 15 \\
\hline
\end{tabular}

TABLE 7 Percentage of liveborn with gestational age less than 37 completed weeks by parental consanguinity

\begin{tabular}{lll}
\hline Parental relationship & Rural & Urban \\
\hline NC & $22 \cdot 5$ & $19 \cdot 2$ \\
C & 19.6 & $20 \cdot 8$ \\
BFC & $15 \cdot 9$ & $17 \cdot 6$ \\
FC & 19.0 & 22.9 \\
UN & $22 \cdot 3$ & $17 \cdot 7$ \\
Total & $21 \cdot 1$ & 19.7 \\
\hline
\end{tabular}


marriages was somewhat less than that for the nonconsanguineous marriages in the rural area, but higher in the urban. However, these differences are not statistically significant. There were no consistent trends by degree of relationship.

\section{BIRTH MEASUREMENTS}

The mean birthweights $( \pm$ SEM) in the rural and urban areas were 2756.8 $\pm 9 \cdot 1 \mathrm{~g}$ and $2871 \cdot 8 \pm 11 \cdot 0$ g, respectively. Nearly $35 \%$ of the rural babies and $28 \%$ of the urban had birthweights of $2500 \mathrm{~g}$ or less. About $7 \%$ of the rural and $6 \%$ of the urban babies had birthweights of $2000 \mathrm{~g}$ or less.

The mean birthweights and the proportions with birthweights of $2500 \mathrm{~g}$ or less, and $2000 \mathrm{~g}$ or less, are shown by type of parental consanguinity among the rural and urban babies in table 8 .

In neither area did the mean birthweight of the consanguineous differ significantly from the nonconsanguineous group. In the rural area, the percentage of babies of $2500 \mathrm{~g}$ or less among the consanguineous was significantly higher than that among the non-consanguineous marriages, although the difference was only $4 \%$. None of the other differences between the proportions was significant.

The mean $( \pm \mathrm{SEM})$ for the crown-heel $(\mathrm{CH})$ and the crown-rump (CR) lengths in the rural area was $47.4 \pm 0.06 \mathrm{~cm}$ and $31.3 \pm 0.05 \mathrm{~cm}$, respectively. The corresponding values in the urban area were $48.3 \pm 0.07 \mathrm{~cm}$ and $31.7 \pm 0.06 \mathrm{~cm}$, respectively. कै The mean lengths and their standard error by $\vec{\circ}$ consanguinity are as shown in table 9 . It is obvious that there are no significant differences in either of $\vec{\omega}$ the two indices of body lengths used by type of marriage in either area.

The observations on head and chest circumferences are given in table 10. The data presented in this table. show that there were no significant differences in $\vec{\sim}$ terms of these indices among the various types of marriage. Further analyses were done by birth order $\frac{5}{5}$ and maternal age, but no further indication of $\vec{T}$ association between these factors and any in- $\mathbb{D}$ breeding effect could be found.

Regression analyses were carried out to describe

TABLE 8 Birthweight by parental consanguinity

\begin{tabular}{|c|c|c|c|c|c|c|c|c|}
\hline \multirow{2}{*}{$\begin{array}{l}\text { Parental } \\
\text { relationship }\end{array}$} & \multicolumn{4}{|l|}{ Rural } & \multicolumn{4}{|l|}{ Urban } \\
\hline & Mean $(g)$ & $S E M(g)$ & $\% \leqslant 2000 \mathrm{~g}$ & $\% \leqslant 2500 \mathrm{~g}$ & Mean $(g)$ & $S E M(g)$ & $\% \leqslant 2000 \mathrm{~g}$ & $\% \leqslant 2500 \mathrm{~g}$ \\
\hline $\begin{array}{l}\text { NC } \\
\text { C } \\
\text { BFC } \\
\text { FC } \\
\text { UN } \\
\text { Total }\end{array}$ & $\begin{array}{l}2772 \\
2740 \\
2775 \\
2737 \\
2730 \\
2757\end{array}$ & $\begin{array}{r}12 \cdot 4 \\
13 \cdot 4 \\
33 \cdot 7 \\
18 \cdot 7 \\
22 \cdot 4 \\
9 \cdot 1\end{array}$ & $\begin{array}{l}6 \cdot 6 \\
8 \cdot 1 \\
5 \cdot 1 \\
8 \cdot 7 \\
8 \cdot 2 \\
7 \cdot 3\end{array}$ & $\begin{array}{l}33 \cdot 2 \\
37 \cdot 2 \\
34 \cdot 3 \\
38 \cdot 1 \\
36 \cdot 8 \\
35 \cdot 1\end{array}$ & $\begin{array}{l}2867 \\
2883 \\
2883 \\
2885 \\
2877 \\
2872\end{array}$ & $\begin{array}{l}13 \cdot 0 \\
20 \cdot 6 \\
47 \cdot 0 \\
28 \cdot 2 \\
37 \cdot 7 \\
11 \cdot 0\end{array}$ & $\begin{array}{l}6 \cdot 5 \\
5 \cdot 6 \\
5 \cdot 1 \\
6 \cdot 0 \\
4 \cdot 8 \\
6 \cdot 3\end{array}$ & $\begin{array}{l}28 \cdot 2 \\
28 \cdot 1 \\
31 \cdot 4 \\
27 \cdot 1 \\
28 \cdot 3 \\
28 \cdot 2\end{array}$ \\
\hline
\end{tabular}

TABLE 9 Mean and SEM of crown-heel and crown-rump lengths by parental consanguinity (cm)

\begin{tabular}{|c|c|c|c|c|c|c|c|c|}
\hline \multirow{3}{*}{$\begin{array}{l}\text { Parental } \\
\text { relationship }\end{array}$} & \multicolumn{4}{|l|}{ Rural } & \multicolumn{4}{|l|}{ Urban } \\
\hline & \multicolumn{2}{|c|}{ Crown-heel } & \multicolumn{2}{|c|}{ Crown-rump } & \multicolumn{2}{|c|}{ Crown-heel } & \multicolumn{2}{|c|}{ Crown-rump } \\
\hline & Mean & $S E M$ & Mean & $S E M$ & Mean & $S E M$ & Mean & $S E M$ \\
\hline $\begin{array}{l}\text { NC } \\
\text { C } \\
\text { BFC } \\
\text { FC } \\
\text { UN } \\
\text { Total }\end{array}$ & $\begin{array}{l}47 \cdot 5 \\
47 \cdot 3 \\
47 \cdot 7 \\
47 \cdot 2 \\
47 \cdot 3 \\
47 \cdot 4\end{array}$ & $\begin{array}{l}0.09 \\
0.09 \\
0.24 \\
0.13 \\
0.16 \\
0.06\end{array}$ & $\begin{array}{l}31 \cdot 1 \\
31 \cdot 1 \\
31 \cdot 5 \\
30 \cdot 9 \\
30 \cdot 9 \\
31 \cdot 1\end{array}$ & $\begin{array}{l}0.07 \\
0.08 \\
0.20 \\
0.11 \\
0.13 \\
0.05\end{array}$ & $\begin{array}{l}48 \cdot 2 \\
48 \cdot 4 \\
49 \cdot 0 \\
48 \cdot 4 \\
47 \cdot 9 \\
48 \cdot 3\end{array}$ & $\begin{array}{l}0.09 \\
0.12 \\
0.26 \\
0.16 \\
0.27 \\
0.07\end{array}$ & $\begin{array}{l}31 \cdot 7 \\
31 \cdot 6 \\
31 \cdot 9 \\
31 \cdot 5 \\
31 \cdot 6 \\
31 \cdot 7\end{array}$ & $\begin{array}{l}0.07 \\
0.10 \\
0.22 \\
0.13 \\
0.23 \\
0.06\end{array}$ \\
\hline
\end{tabular}

TABLE 10 Mean and SEM of head circumference and chest circumference by parental consanguinity (cm)

\begin{tabular}{|c|c|c|c|c|c|c|c|c|}
\hline \multirow{3}{*}{$\begin{array}{l}\text { Parental } \\
\text { relationship }\end{array}$} & \multicolumn{4}{|l|}{ Rural } & \multicolumn{4}{|l|}{ Urban } \\
\hline & \multicolumn{2}{|c|}{ Head circumference } & \multicolumn{2}{|c|}{ Chest circumference } & \multicolumn{2}{|c|}{ Head circumference } & \multicolumn{2}{|c|}{ Chest circumference } \\
\hline & Mean & SEM & Mean & $S E M$ & Mean & $S E M$ & Mean & $S E M$ \\
\hline $\begin{array}{l}\text { NC } \\
\text { C } \\
\text { BFC } \\
\text { FC } \\
\text { UN } \\
\text { Total }\end{array}$ & $\begin{array}{l}33 \cdot 7 \\
33 \cdot 5 \\
33 \cdot 4 \\
33 \cdot 5 \\
33 \cdot 5 \\
33 \cdot 6\end{array}$ & $\begin{array}{l}0.05 \\
0.05 \\
0.14 \\
0.08 \\
0.09 \\
0.04\end{array}$ & $\begin{array}{l}32 \cdot 5 \\
32 \cdot 3 \\
32 \cdot 3 \\
32 \cdot 2 \\
32 \cdot 3 \\
32 \cdot 4\end{array}$ & $\begin{array}{l}0.06 \\
0.06 \\
0.16 \\
0.09 \\
0.09 \\
0.04\end{array}$ & $\begin{array}{l}33.9 \\
33.9 \\
34.0 \\
33.9 \\
33.9 \\
33.9\end{array}$ & $\begin{array}{l}0.05 \\
0.07 \\
0.14 \\
0.09 \\
0.14 \\
0.04\end{array}$ & $\begin{array}{l}32 \cdot 6 \\
32 \cdot 5 \\
32 \cdot 4 \\
32 \cdot 5 \\
32 \cdot 7 \\
32 \cdot 6\end{array}$ & $\begin{array}{l}0.06 \\
0.08 \\
0.18 \\
0.11 \\
0.18 \\
0.05\end{array}$ \\
\hline
\end{tabular}


TABLE 11 Relationship of inbreeding to incidence of congenital malformations and immaturity: estimated values of intercept $(A)$ and regression coefficient $(B)$

\begin{tabular}{llllll}
\hline Attribute & \multicolumn{2}{l}{ Rural } & & \multicolumn{2}{l}{ Urban } \\
\cline { 2 - 3 } \cline { 5 - 6 } \cline { 5 - 6 } & $A$ & $B$ & & $A$ & $B$ \\
\hline Congenital malformations & 0.0069 & 0.0171 & & 0.0102 & 0.0158 \\
Gestational age $<37$ weeks & 0.242 & -0.107 & & 0.215 & 0.186 \\
Birthweight $\leqslant 2000 \mathrm{~g}$ & 0.068 & 0.197 & 0.067 & -0.124 \\
\hline
\end{tabular}

the relationship of inbreeding to incidence of congenital malformations and certain birth measurements using the following exponential curve

$$
P_{i}=1-\exp \left\{-\left(\alpha+\beta F_{i}\right)\right\}
$$

where $P_{i}$ is the estimated proportion of subjects with, for example, congenital malformation, prematurity, etc, in the sub-group based on type of parental consanguinity, and $F_{i}$ is the Wright's coefficient of inbreeding for that sub-group. The maximum likelihood estimates of $\alpha$ and $\beta$ were obtained through weighted regression techniques using iterative procedures. ${ }^{1}$ The findings are shown in table 11. None of the regression coefficients attain statistical significance.

\section{Discussion}

Much evidence exists to show that the intrauterine growth of the fetus is greatly influenced by such environmental factors as nutrition, oxygenation, smoking, infection, and placental function. ${ }^{5-7}$ On the other hand, the basic genetic endowment of the offspring is also important and provides the potential for growth and development. ${ }^{8}$ Observations on plants and animals lend support to certain generalisations, such as the decreased size and vigour which follows inbreeding in normally outbred populations. These results are attributed to the manifestation in the homozygous state of genes which are ordinarily heterozygous. At the same time, there are a number of reports on 'hybrid vigour', or the effect of heterosis, when the offspring of cross-breeding physically surpass the parents themselves. ${ }^{9}$

Since consanguinity implies greater homozygosity in the offspring for certain alleles, continued inbreeding should lead to more and more homozygosity, which in turn is manifested phenotypically. However, the human fetus is a very complex organism and even the closest possible types of consanguineous marriages do not consistently correspond with the types of inbreeding lines set up in a laboratory for genetic experiments. Apart from the problem of measurement of homozygosity, most inbreeding effects cannot be easily detected because of the polygenic and multifactorial inheritance of human traits.

In the present investigation, the effects of inbreeding were looked for in the incidence of congenital anomalies, length of gestation, and body measurements. All these parameters are subject to great variation and are peculiarly difficult to assess, as described below.

The aetiology of congenital malformations includes both genetic and environmental factors, and genetic predisposition seems to be multifactorially determined rather than through the action of a single mutant gene. ${ }^{10-12}$ Most studies exploring the role of inbreeding on congenital anomalies are retrospective in nature and based on cases in hospital. Although a high rate of parental consanguinity has been observed among those affected, ${ }^{13-15}$ in most studies no serious search seems to have been made for other factors in the family that might have contributed to the congenital malformations, ${ }^{16}$ nor were inferences drawn after comparison with adequate control groups. ${ }^{17}$

Evidence from studies done so far shows some increase in the incidence of congenital malformations with inbreeding, more so for those with a possible genetic origin and those with complex manifestation. ${ }^{2 a} 19$ The present study, based on prospective data on externally manifested anomalies through standard screening procedures of liveborn babies, does not show significant inbreeding effects. The late fetal death rates (those occurring on or after 28 weeks' gestation) in the non-consanguineous and consanguineous marriages were $1.9 \%$ and $2.1 \%$, respectively, in the rural areas, while they were $2.3 \%$ and $2.5 \%$, respectively, in the urban areas ${ }^{1}$; these differences were not statistically significant. It is possible that examination of all births, including these late fetal losses, as well as more comprehensive screening, would have resulted in a larger number of anomalies being discovered; however, this is unlikely to change the conclusions arrived at in this paper.

Data on the effects of inbreeding on gestational age are hard to find. Morton ${ }^{2}$ examined data on Japanese babies, and reported that there were no significant effects of inbreeding on gestational age. The duration of pregnancy cannot be accurately determined because of the uncertainty about the day of fertilisation or the moment the ovum begins to develop. The use of the first day of the last menstrual period is merely a matter of convenience. The duration of normal pregnancy is known to vary with the sex of the baby, ${ }^{20}$ with geographic regions and race, ${ }^{21}$ and with the normal length of the mother's menstrual cycle. ${ }^{22}$ In a Brazilian study, it was estimated that the proportion of infants delivered after only 7 or 8 months' gestation was 
$1.6 \%$ in the consanguineous group and $3.2 \%$ in the control; this difference was not statistically significant. ${ }^{23}$ This was on the basis of all liveborn children who were alive at the time of the survey. A reanalysis, including all liveborn children, came to the same conclusion. The present study reveals no significant effects of inbreeding on gestational age.

In characteristics that are multifactorially determined, such as anthropological measurements, where environment plays a substantial role, inbreeding effects may take longer to become manifest, and more studies are needed to explore this phenomenon. Dahlberg ${ }^{24}$ suggested that inbreeding may have a greater effect on adult than on juvenile characteristics. However, there do not appear to be sufficient empirical studies to confirm this feature even in other mammals. The inbreeding effect seems to be less for adult measurements than for the rate of growth, as if the inbred animals attained nearly the same final size but approached it more slowly. ${ }^{25}$ Birthweight is known to differ with race, sex, and geographic regions, with maternal characteristics such as height, weight, and parity, and with several other familial characteristics. Maternal nutrition during the third trimester particularly seems to have a significant effect on birthweight. In a country such as India, where chronic undernutrition and malnutrition are common, the birthweights would probably be influenced much more by environmental factors than by genetic ones.

In a study of 26 anthropometric variables among 480 Mexicans living in Paracho, Michigan, and in 609 Peruvians of the province of Iambayeque on the north coast of Peru, it was found that there was a significant lowering for seven of the variables in the Mexicans only; neither the Peruvians nor the total series showed such effects with inbreeding. ${ }^{26}$ Among the Japanese, there appears to be some depression (about $30 \mathrm{~g}$ ) with inbreeding for birthweight, and with the large numbers studied this was statistically significant. ${ }^{2}$ No such inbreeding depressions were seen in the present studies.

Since fetal growth and development in the human tend to be complex interactions of both genetic and environmental influences, it is perhaps not surprising to find a lack of significant inbreeding effect on the incidence of congenital malformations, gestational age, and anthropometrics at birth. The fact that the findings in the rural and urban areas were often consistent provides less support for the hypothesis that genetic effects are obscured in the presence of large environmental effects, and predicates that there may be at least one other explanation for the lack of major differences in several aspects of human reproduction when studied by parental consanguinity. It does suggest that the long term practice of inbreeding reduces the burden of deleterious genes $\stackrel{\overparen{P}}{?}$ and thus the adverse effects upon fetal growth and $\vec{F}$ development.

We are deeply indebted to the field investigators, $\frac{\bar{\sigma}}{\bar{c}}$ their supervisors and co-ordinators, and to the $\frac{\bar{\sigma}}{\bar{\sigma}}$ statistical personnel, without whose wholehearted $\stackrel{\mathbb{Q}}{2}$ co-operation and hard work a study of this type is virtually impossible. To the public and their leaders $\vec{\circ}$ we owe a debt of gratitude. We are especially grateful for the statistical assistance received from $\vec{\omega}$ Mr V R Subramaniam and for the secretarial help? of Mr V Krishnan.

\section{References}

1 Rao PSS, Inbaraj SG, Inbreeding effects on human reproduction in Tamil Nadu of South India. Ann Hum Genet 1977;41:87-98.

2 Morton NE. Empirical risks in consanguineous marriages: TT birthweight, gestation time, and measurements of $\frac{\mathbb{O}}{\mathrm{O}}$ infants. Am J Hum Genet 1958;10:344-9.

2a Yanase $T$. Heredo-clinical investigation concerning the ֶِ highly inbred villages in Western Japan, especially Shiiba-mura, Miyazaki-ken, 1951. Quoted by Schull WJ, $\vec{\bullet}$ Neel JV. In: The effects of inbreeding on Japanese children. New York: Harper and Row, 1965.

3 Rao PSS, Inbaraj SG. Inbreeding in Tamil Nadu, South $\square$ India. Soc Biol 1977;24:281-8.

4 Rao PSS, Inbaraj SG. Inbreeding effects on fertility and sterility in southern India. $J$ Med Genet 1979;16:24-31.

5 Roberts DF. Environment and the fetus. In: Roberts DF, ֶ Thomson AM, eds. The biology of human fetal growth. $\mathbb{2}$ London: Taylor and Francis, 1976:267-83.

6 Yerushalmy J. The relationship of parents' cigarette $\overrightarrow{\vec{O}}$ smoking to outcome of pregnancy-implications as to 3 the problem of inferring causation from observed associa- $?$ tions. Am J Epidemiol 1971;93:443-56.

7 Ganguly M, Elwood JH, MacKenzie G. Factors associated with 'low' and 'high' birthweight. $A m J$ Epidemiol 3 1972;96:161-7.

8 Wright EV. Chromosomes and human fetal development. In: Roberts DF, Thomson AM, eds. The biology of human. fetal growth. London: Taylor and Francis, 1976:237-52.

- Altenburg E. In: Genetics. chap 7. New York: Holt, Rinehard, Winston, 1957.

10 Carter CO. The inheritance of common congenitalo malformations. In: Steinberg AG, Bearn AG, eds. Progress in medical genetics. vol 4. New York: Grune and Stratton, 1965:59-84.

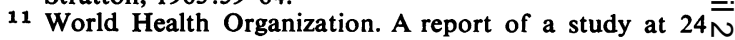
centers on congenital malformations. WHO Bulletin $\mathrm{N}$ 1966;34(suppl):1-127.

12 Klingberg MA, Chen R, Chemka J, Levin S. An epidemio-유 logical study of congenital malformations among different $\mathrm{W}$ ethnic and social groups in Israel. Dev Med Child Neurolర్ $1971 ; 13: 735-45$.

13 Costeff H, Cogen BE, Weller L. Parental consanguinity among Israeli mental retardates. Acta Paediatr Scand $\mathbb{\Phi}$ $1972 ; 61: 452-8$.

14 Penrose LS. A note on the prevalence of genes for $\square$ deleterious recessive traits in man. Ann Hum Genet $\bar{O}$ 1957;21:222-3.

15 Sinclair S. Familial mental retardation and parental $\stackrel{\mathbb{P}}{\mathbb{Q}}$ consanguinity. Indian J Med Res 1971 ;59:1050-3.

16 Chung CS, Memecher RW, Larsen IJ. Genetic and . 
epidemiological studies of clubfoot in Hawaii. Hum Hered 1969;19:321-42.

17 Centerwall WR, Centerwall SA. Consanguinity and congenital anomalies in south India: a pilot study. Indian J Med Res 1966;54:1160-7.

19 Schull WJ. Empirical risks in consanguineous marriages: sex ratio, malformations, and viability. Am J Hum Genet 1958;10:294-343.

20 Karn MN, Penrose LS. Birthweight and gestation time in relation to maternal age, parity and infant survival. Ann Eugen 1951 ;15:206-33.

21 Erhardt CL, Chase HC. Ethnic group, education of mother, and birthweight. Am J Public Health 1973;63: 16-26.

22 Hsia DY. In: Human developmental genetics. chap 3, 4, 5. Chicago: Yearbook Publishers, 1968.
23 Marcallo FA, Freire-Maia N, Azevedo JBC, Simoes IA. Inbreeding effect on mortality and morbidity in south Brazilian populations. Ann Hum Genet 1964;27:203-18.

24 Dahlberg G. Inbreeding in man. Genetics 1929;14:421-54

25 Bradford GE, Chapman AB, Grummer RH. Effects of inbreeding, selection, linecrossing, and topcrossing in swine. I. Inbreeding and selection. J Anim Sci 1958;17: 426-40.

26 Lasker G, Kaplan B. Anthropometric variables in the offspring of isonymous marriage. Hum Biol 1974;46: 713-7.

Requests for reprints to Professor P S S Rao, Department of Biostatistics, Christian Medical College, Vellore 632 002, Tamil Nadu, India. 